\title{
Contribution of Radioiodine Thyroid Uptake and Scintigraphy to the Diagnosis of Hyperthyroidism
}

\author{
Md. Monirul Haque ${ }^{*}$, Alamin'1, Md. Faruq Hossain', Md. Sanowar Hossain², Md. Selim Reza² \\ ${ }^{1}$ Department of Physics, University of Rajshahi, Rajshahi, Bangladesh \\ ${ }^{2}$ Institute of Nuclear Medicine and Allied Sciences (INMAS), BAEC, Dhaka, Bangladesh \\ Email: *mhpdru@gmail.com
}

How to cite this paper: Haque, M.M., Alamin, Hossain, M.F., Hossain, M.S. and Reza, M.S. (2018) Contribution of Radioiodine Thyroid Uptake and Scintigraphy to the Diagnosis of Hyperthyroidism. World Journal of Nuclear Science and Technology, 8, 70-77.

https://doi.org/10.4236/wjnst.2018.82007

Received: January 9, 2018

Accepted: April 8, 2018

Published: April 11, 2018

Copyright $\odot 2018$ by authors and Scientific Research Publishing Inc. This work is licensed under the Creative Commons Attribution International License (CC BY 4.0).

http://creativecommons.org/licenses/by/4.0/

\begin{abstract}
In total 184 studies, which included thyroid uptake and scintigraphy, were performed in 68 hyperthyroid patients: $67 \%$ female and 33\% male to investigate their thyroid conditions. The aim of the present study was to illustrate the role of uptake and scintigraphy tests in determining the thyroid status of hyperthyroid patients. The uptake study was performed by oral administration of $100-200 \mu \mathrm{Ci}$ of ${ }^{131} \mathrm{I}$ as sodium-iodide and counting the radioactivity at 2 and $24 \mathrm{hrs}$, whereas thyroid scintigraphy was performed 20 minutes after an intravenous injection of $2-4 \mathrm{mCi}$ of ${ }^{99 m} \mathrm{Tc}$-pertechnetate. The present results of thyroid uptake and scintigraphy successfully identified the thyroid condition in different states. The present results were also compared with some reported data and found to be fair in good agreement.
\end{abstract}

\section{Keywords}

Radioiodine Uptake, Scintigraphy, Hyperthyroidism

\section{Introduction}

Butterfly-shaped thyroid gland in the neck is one of the endocrine glands, which produces, stores and releases thyroid hormones, as they are needed in the body. Thyroid hormones control the rate of many activities in the body including how fast calories burn and how fast heart beats. All of these activities are body's metabolism. Extreme excess of thyroid hormone secretion causes the basal metabolic rate (BMR) to raise $60 \%-100 \%$ above the normal [1]. Complete lack of these hormones secretion, on the other hand, can cause BMR to fall $40 \%-50 \%$ below the normal. Thyroid hormones also play the key roles in growth and de- 
velopment, particularly in brain development [2] [3] [4] [5] [6]. Changes in thyroid function can impact greatly on reproductive function before, during and after conception [7] [8] [9]. It is, therefore, to evaluate the functional status of thyroid gland that is of a significant practical interest.

Disorders of thyroid gland are among the most common endocrine maladies. Thyroid diseases manifest mainly by qualitative or quantitative alteration in hormone secretion. Symptoms of thyroid disorders are due to the overproduction (hyperthyroidism) or underproduction (hypothyroidism) of thyroid hormones. After assaying the thyrotropin and thyroid hormone levels, radioactive iodine uptake (RAIU) measurement and scintigraphy are often recommended as the first-line investigation [10] to be confirmed the hyperfunction of thyroid gland. RAIU and scintigraphy are, therefore, now useful tools for evaluating thyroid status.

Radioactive iodine uptake is a measure of the rate of accumulation of radioactive tracer by the thyroid and the ability of it to trap that tracer. Scintigraphy, on the other hand, is the use of gamma cameras to capture emitted radiation from internal radioisotopes to create two-dimensional images. The thyroid uptake is performed to evaluate the function of the gland. Whereas, the thyroid scan is used to determine the size, shape and position of the thyroid gland. This test is also done to check thyroid cancer, to evaluate thyroid nodules or goiter, and to find the causes of an overactive thyroid gland. In RAIU process, the patient swallows radioactive ${ }^{131} \mathrm{I}$ in the form of capsule or fluid, and its absorption by the thyroid is studied at various intervals from 1 to $48 \mathrm{hrs}$ with the aid of a scintillation counter. The normal ranges of radioactive ${ }^{131} \mathrm{I}$ thyroid uptake reported in the literature [11] [12] [13] are: $3 \%-12 \%$ at $2 \mathrm{hrs;} 6 \%-18 \%$ at $4 \mathrm{hrs}$; and $8 \%-$ $25 \%$ at $24 \mathrm{hrs}$. These values, however, are interpreted loosely, because of the variation of equipment, standards, uptake phantoms, and subject individuals from populations with various levels of iodine intake. A high RAIU taken by the gland is usually found in the hyperthyroidism and a low uptake in the hypothyroidism condition [14]. Encouraged by our recent measurements [15] [16], the aim of the present study is to evaluate the contribution of RAIU test along with thyroid scintigraphy in determining the status of thyroid gland of the hyperthyroid patients, and thereby contribute some useful data in literature.

The rest of the paper is organized as follows. Section 2 outlines the materials and method. In Section 3, the present results are discussed by comparing them with reported data. Section 4 concludes the findings with a brief summary.

\section{Materials and Method}

\subsection{Patients Preparation}

There are 68 subjects (33\% males and $67 \%$ females) ranging in age from 16 to 70 years included in the study. The subjects were referred for evaluation of thyroid function in a routine practice. The uptake study consisted of oral administration of 3.7 - 7.4 MBq (100 - $200 \mu \mathrm{Ci})$ of ${ }^{131} \mathrm{I}$ as sodium-iodide. Prior to oral adminis- 
tration of the isotope, a history to rule out the intake of any iodine containing agents or drugs known to affect thyroid function was asked from all the patients. Patients with deficient records, e.g. incomplete patient records, were excluded.

\subsection{Uptake Measurements}

The principle of uptake measurement is relatively simple. The amount of gamma-radiation given off by radioiodine, which has been accumulated by the thyroid at a certain time after its administration to the patient is compared with the amount of gamma-radiation emitted by the total dose administered to the patient. In the ideal case, both measurements should be done under identical conditions. In the present study, the radioactivity counts were taken at $6 \mathrm{~cm}$, using a gamma probe (CANBERRA 2007p) consisting of a collimated sodium-iodide crystal with a cylindrical straight-bore collimator connected to a pulse height analyzer (PHA) and scalar. Neck counts, lower thigh counts (body background), counts of the administered dose, and room background counts were obtained at each counting session. A spacer was used so that the same distance is always maintained whenever counting is taken place. Using data from these steps, the RAIU both at 2 and $24 \mathrm{hrs}$ were calculated as the percentage of the administered dose.

\subsection{Thyroid Scintigraphy}

Scintigraphy is a diagnostic test in nuclear medicine, where radioisotopes attached to drugs that travel to a specific organ are taken internally, and the emitted radiation is captured by external detectors to form two dimensional images. It can help the physician to determine the size, shape, and position of the thyroid gland. In the present study, the patients were first given a $2 \mathrm{mCi}(74 \mathrm{MBq})$ intravenous dose of ${ }^{99 \mathrm{~m}} \mathrm{Tc}$-pertechnetate. Drinking water was given immediately before performing imaging to flux away any secreted radionuclide in saliva. The patient was placed supine, and the gamma camera was placed over the neck 30 $\mathrm{cm}$ above the skin surface. The radioactivity in the neck was continuously recorded using a low-energy high resolution parallel-hole collimator.

\section{Results and Discussion}

24 hrs RAIU has become the benchmark of iodine accumulation by the thyroid gland and with the development of the rectilinear scanner by Cassen in 1951, the 24 hrs uptake and scan have become the world-standard test for anatomical mapping and functional assessment of the thyroid. Though early images are inferior to $24 \mathrm{hrs}$ scintigrams [17], successful thyroid imaging at 2 to $6 \mathrm{hrs}$ after oral administration of radioiodine is also possible [18]. Therefore, two separate uptake measurements, at 2 to $6 \mathrm{hrs}$ and $24 \mathrm{hrs}$, are often performed in clinical practices.

The present results for RAIU measured at $2 \mathrm{hrs}$ as well as $24 \mathrm{hrs}$ are summarized in Table 1 . The Mean \pm SD of RAIU values were found to be $37 \% \pm 15 \%$ at 
2 hrs with range $16 \%-77 \%$ and $61 \% \pm 13 \%$ at 24 hrs with range $35 \%-89 \%$, respectively. The uncertainties quoted in the values represent the statistical and systematic errors. The frequency histograms of 2 and 24 hrs RAIU values observed in this study are depicted in Figure 1. As the frequency histograms revealed a non-Gaussian data distribution, the mean and standard deviation $( \pm S D)$ are not included in these normal distribution curves.

The box-plot analysis of 2 hrs RAIU values indicates that about $73 \%$ of the hyperthyroid patients have RAIU values that ranged from $16 \%$ to $45 \%$ and about $90 \%$ have uptake range from $16 \%$ to $55 \%$. The 24 hrs RAIU distribution curve

Table 1. RAIU values at 2 and 24 hrs measurements. SD stands for standard deviation.

\begin{tabular}{ccc}
\hline & \multicolumn{2}{c}{ Uptake (\%) at } \\
\cline { 2 - 3 } Class & 2 hrs & 24 hrs \\
\hline Range & $16-77$ & $35-89$ \\
Average \pm SD & $37 \pm 15$ & $61 \pm 13$ \\
\hline
\end{tabular}

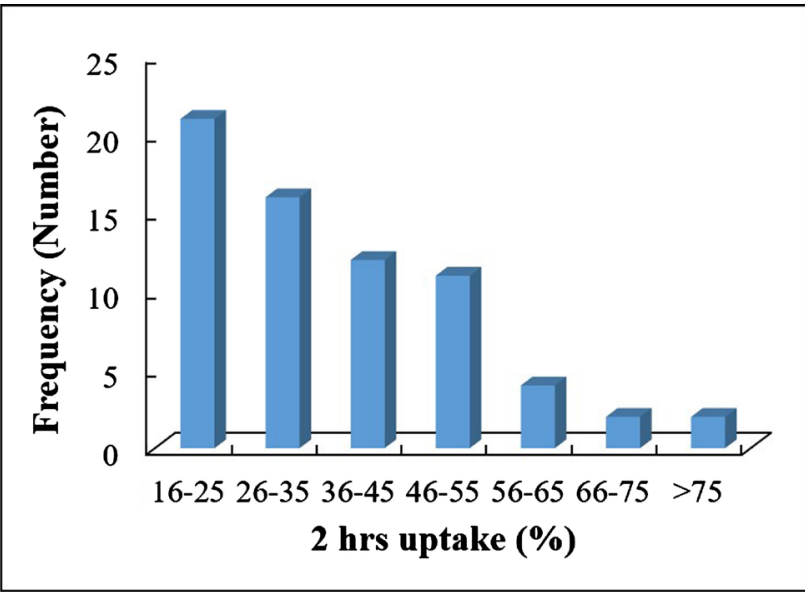

(a)

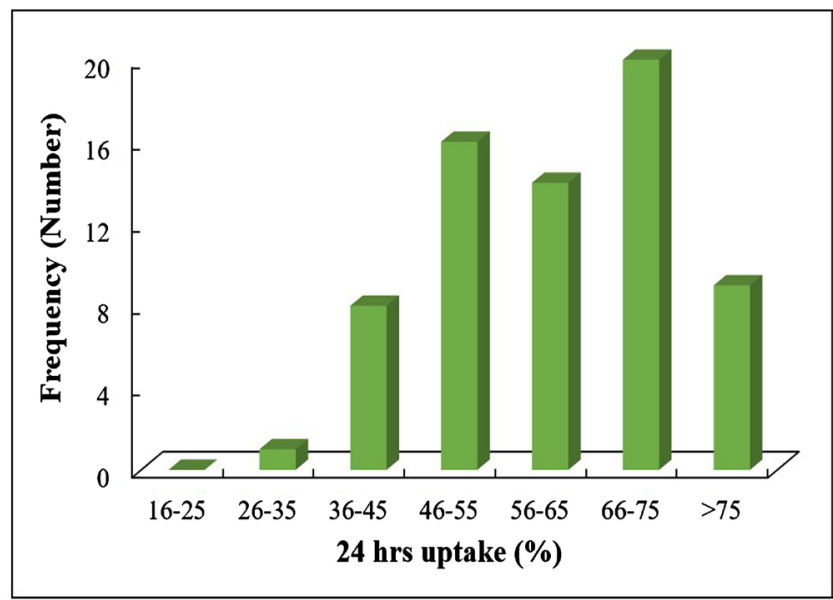

(b)

Figure 1. (Color online) Frequency histograms of uptake values measured at (a) $2 \mathrm{hrs,}$ and (b) $24 \mathrm{hrs}$. 
shows that about $65 \%$ of the hyperthyroid patients have uptake range of $46 \%$ $75 \%$ and about $80 \%$ individuals have uptake range of $36 \%-75 \%$. The present study gives a good separation of hyperthyroid patients and none of them have uptake value within or below the normal range both at 2 and 24 hrs measurements. However, it is evident from Figure 1 that majority of the studied patients have 2 hrs RAIU values near the threshold whereas 24 hrs RAIU values far from the threshold. It may, therefore, be mentioned that uptake measurements at 24 hrs is more reliable than at $2 \mathrm{hrs}$.

It is evident from literature [19] [20] that the most common cause of hyperthyroidism is Graves' disease, which accounts for approximately $60 \%$ to $80 \%$ [21] [22] [23] [24] of cases in the United States, and in other countries where the population has adequate iodine intake. Toxic multinodular goiter is the second leading cause of hyperthyroidism and is more prevalent in populations with greater iodine deficiency. This is irregular thyroid enlargement containing both functioning and non-functioning nodules. It is commoner in older women [25] [26]. In the present study, all the studied patients, on the basis of ${ }^{99 \mathrm{~m}} \mathrm{Tc}$ scan findings, were divided into Graves' disease (GD), multinodular goiter (MNG), toxic adenoma (TA) and thyromegaly (TM). As shown in Figure 2, the most common classification reached on the basis of scan reports is Graves' disease (51\%), followed by multinodular goiter (24\%), toxic adenoma (15\%) and thyromegaly (10\%). The present results are, therefore, fairly in good agreement with the reported data.

It was reported [24] [27] previously that Graves' disease is approximately 5 to 10 times more common in women than in men; the incidence is similar among Caucasian and Asian population, but lower among African Americans. In order to compare the present results with these reported data, we further analyzed the Graves' disease patients stratifying into two subgroups: female and male. The

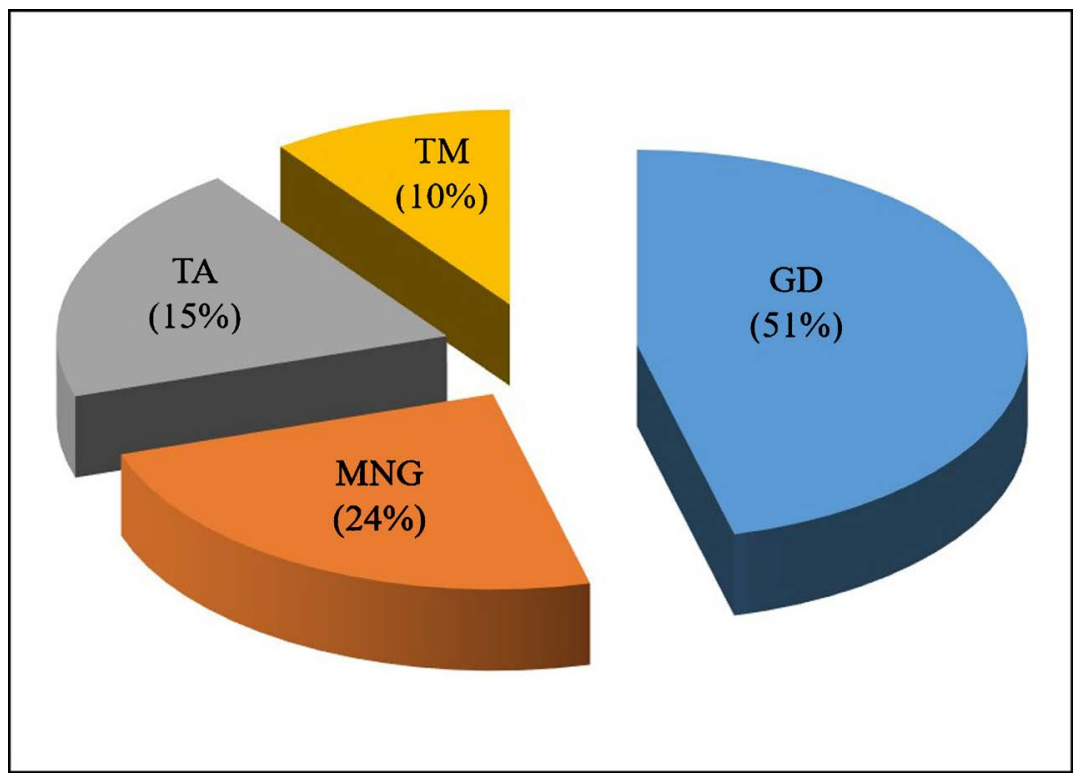

Figure 2. (Color online) Graphical representation of sample distribution on scan reports. 
sample distribution as a function of age for both of these two subgroups is depicted in Figure 3. The classification indicates that the hyperthyroid patients developing Graves' disease are about $80 \%$ female, which is about 4 times the male. This result is, however, slightly lower than the reported value. This may be argued that Bangladesh is an iodine deficient zone and Laurberg et al. [28] reported that iodine-deficient populations have a much lower incidence of Graves' disease.

Figure 3 also illustrates that about $70 \%$ of the patients with Graves' disease are within the age of 40 years, and about $85 \%$ are within 50 years. It is very clear from this scenario that the patients with Graves' disease are predominantly in the younger age groups, and these results are fairly in good agreement with those reported by Devies and Larsen [29] that patients younger than age of 40 years are at the highest risk for the development of Graves' disease.

\section{Conclusions}

The present study consists of 68 hyperthyroid samples, among which $67 \%$ are female and $33 \%$ are male. In total, 184 studies have been performed including uptake measurements and scintigraphy. ${ }^{131}$ I-sodium-iodide uptakes absorbed at $2 \mathrm{hrs}$ as well as at $24 \mathrm{hrs}$ are presented. The present study provides a good separation of hyperthyroid patients from others, and none of them has uptake lower than or within the normal range. The reports of scintigraphic scan also differentiated successfully the thyroid condition in different states. Present study also shows that the most common cause of hyperthyroidism is Graves' disease (46\%) followed by multinodular goiter (24\%), toxic adenoma (20\%) and thyromegaly $(10 \%)$. As most of the patients are younger (age $\leq 40$ years), they all are at higher risk, especially the women, because the Graves' disease is more common in them. Our observations were also compared with the reported series and found to be excellent agreement in some cases. We, therefore, expect our study will contribute some useful data in literature, and provide a guideline for the diagnosis

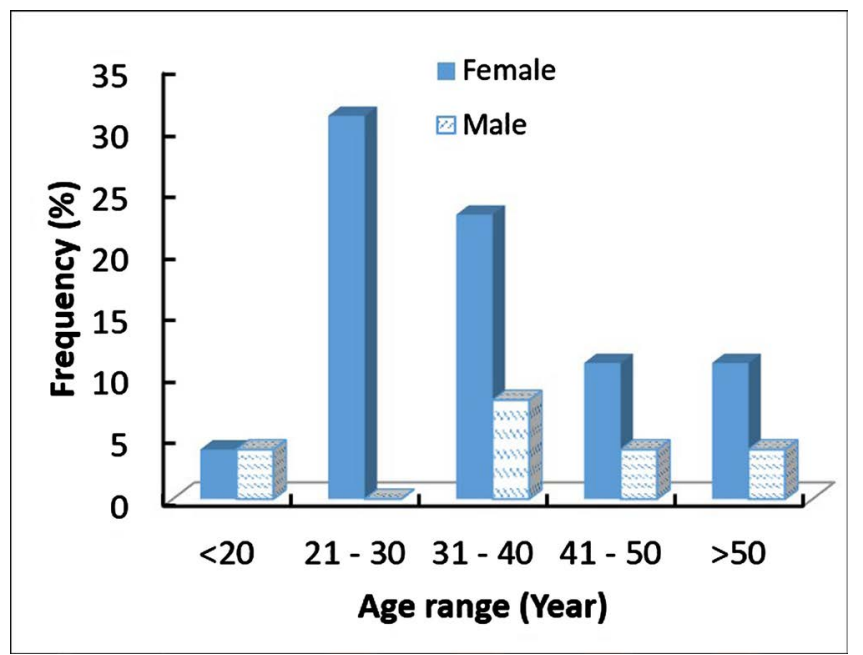

Figure 3. (Color online) Frequency histograms of Graves' disease patients. 
and management of hyperthyroidism.

\section{Acknowledgements}

This study has been carried out within the framework of research project No. 37-5/52/UGC/science-7/17-18 supported by the Faculty of Science, Rajshahi University. The co-operative help of all the staffs of INMAS, Dhaka is appreciated.

\section{References}

[1] Hall, J.E. (2015) Guyton and Hall Textbook of Medical Physiology. Elsevier Health Sciences, Philadelphia, p. 107.

[2] Anderson, G.W. (2008) Thyroid Hormone and Cerebellar Development. Cerebellum, 7, 60-74. https://doi.org/10.1007/s12311-008-0021-4

[3] Bernal, J. (2002) Action of Thyroid Hormone in Brain. Journal of Endocrinological Investigation, 25, 268-288.

[4] Kohrle, J. (2000) Thyroid Hormone Metabolism and Action in the Brain and Pituitary. Acta Medica Austriaca, 27, 1-7. https://doi.org/10.1046/j.1563-2571.2000.00101.x

[5] Koibuchi, N. and Chin, W.W. (2000) Thyroid Hormone Action and Brain Development. Trends in Endocrinology \& Metabolism, 11, 123-128. https://doi.org/10.1016/S1043-2760(00)00238-1

[6] Thompson, C.C. and Potter, G.B. (2000) Thyroid Hormone Action in Neural Development. Cerebral Cortex, 10, 939-945. https://doi.org/10.1093/cercor/10.10.939

[7] Bongers-Schokking, J.J. (2001) Pre and Postnatal Brain Development in Neonates with Congenital Hypothyroidism. Journal of Pediatric Endocrinology and Metabolism, 14, 1463-1468.

[8] Rovet, J. and Daneman, D. (2003) Congenital Hypothyroidism: A Review of Current Diagnostic and Treatment Practices in Relation to Neuropsychologic Outcome. Pediatric Drugs, 5, 141-149. https://doi.org/10.2165/00128072-200305030-00001

[9] Klein, R.Z. and Mitchell, M.L. (1999) Maternal Hypothyroidism and Child Development: A Review. Hormone Research, 52, 55-59. https://doi.org/10.1159/000023435

[10] Alsharif, A.A., Abujbara, M.A., Chiacchio, S., Ajlouni, K.M. and Mariani, G. (2010) Contribution of Radioiodine Uptake Measurement and Thyroid Scintigraphy to the Differential Diagnosis of Thyrotoxicosis. Hellenic Journal of Nuclear Medicine, 13, 132-137.

[11] Salvatore, D., Davies, T.F., Schlumberger, M.J., Hay, I.D. and Larsen, P.R. (2011) Thyroid Physiology and Diagnostic Evaluation of Patients with Thyroid Disorders. In: Melmed, S., Polonsky, K., Larsen, P.R. and Kronenberg, H., Eds., Williams Textbook of Endocrinology, 12 Edition, Saunders, Philadelphia, 327-350.

[12] Rosenthal, M.S. (2009) The Thyroid Source Book. McGraw-Hill, New York.

[13] Balon, H.R., Silberstein, E.B., Charkes, M.D., Royal, H.D., Sarkar, S.D. and Donohoe, K.J. (2013) Society of Nuclear Medicine Procedure Guideline for Thyroid Uptake Measurement. Thyroid, 3, 1-4.

[14] Bahn, R.S., Burch, H.B., Cooper, D.S., Garber, J.R., Greenlee, M.C., et al. (2011) Hyperthyroidism and Other Causes of Thyrotoxicosis: Management Guidelines of the American Thyroid Association and American Association of Clinical Endocri- 
nologists. Thyroid, 21, 593-646.

[15] Hossain, M.F., Haque, M.M., Hossain, M.S. and Reza, M.S. (2017) Correlation of Serum T4, T3 and TSH Levels Radioiodine Thyroid Uptakes. IOSR Journal of Nursing and Health Science, 6, 13-16.

[16] Ali, L., Haque, M.M. and Islam, M.R. (2016) The Study of Thyroid Physiology using 131I-Sodium-Iodide Uptake Measurement. Academic Journal of Chemistry, 1, 40-45.

[17] Ryo, U.Y., Vaidya, P.V., Schneider, A.B., et al. (1983) Thyroid Imaging Agents: A Comparison of 1-123 and Tc-99m Pertechnetate. Radiology, 148, 819-822.

[18] Atkins, H.L. (1984) The Thyroid. In: Freeman and Johnson's Clinical Radionuclide Imaging, 3rd Edition, Grune and Stratton, Orlando, 1280.

[19] Howlett, T.A. (2005) Endocrine Disease, In: Kumar, P. and Clark, M., Eds., Clinical Medicine, 6th Edition, Elsevier Saunders, Edinburgh.

[20] Qari, F.A. (2007) Trends in the Diagnostic and Therapeutic Approach to Graves' Disease at a University Hospital. http://www.bhj.org/journal/april2005/htm/original_trends_122.htm

[21] Crosignani, P.G. (2003) Breast Cancer and Hormone-Replacement Therapy in the Million Women Study. Maturitas, 46, 91-92.

[22] Pearce, E.N. (2006) Diagnosis and Management of Thyrotoxicosis. BMJ, 332, 1369-1373. https://doi.org/10.1136/bmj.332.7554.1369

[23] Biondi, B. and Cooper, D.S. (2008) The Clinical Significance of Subclinical Thyroid Dysfunction. Endocrine Reviews, 29, 76-131.

[24] Weetman, A.P. (2000) Graves Disease. The New England Journal of Medicine, 343, 1236-1248.

[25] Robbins, S.L., Cotran, R.S., Kumar, V. and Collins, T. (1999) Pathologic Basis of Disease. 6th Edition, W.B. Saunders, Philadelphia, 1130-1141.

[26] Ziessman, H.A., O’Malley, J.P. and Thrall, J.H. (2013) Nuclear Medicine: The Requisites E-Book. Elsevier Health Sciences, Amsterdam.

[27] Metchick, L.N., Carlone, V. and Haag, B.L. (2005) Clinical Review Article. Hospital Physics, 47, 46-56.

[28] Laurberg, P., Jorgensen, T., Perilld, H., Ovesen, L., Knudsen, N., et al. (2006) The Danish Investigation on Iodine Intake and Thyroid Disease, DanThyr: Status and Perspectives. European Journal of Endocrinology, 155, 219-228.

[29] Davies, T.F. and Larsen, P.R. (2003) Thyrotoxicosis. In: Williams, R.H., Larsen, P.R., Konenberg, H.M., et al., Eds., Williams Text Book of Endocrinology, 10th Edition, Saunders, Philadelphia, 379. 